\title{
Induced delusional disorder: a case report of Folie A' Famille
}

Konstantinos Katsigiannopoylos*1, Pandelis Pazarlis ${ }^{1}$, Georgios Zambioglou1, Maria Papadimitriou ${ }^{2}$, Vasilios Dinas ${ }^{3}$, Ioanna Gollia ${ }^{2}$, Christos Skaropoulos ${ }^{3}$, Dimitrios Sevris ${ }^{4}$, Anastasios Kanistras ${ }^{2}$ and Anastasia Karastergiou ${ }^{1}$

\author{
Address: ${ }^{1} \mathrm{D}$ ' Acute Ward, Psychiatric Hospital, Thessaloniki, Greece, ${ }^{2} \mathrm{C}^{\prime}$ Acute Ward, Psychiatric Hospital, Thessaloniki, Greece, ${ }^{3} \mathrm{~A}$ ' Acute Ward, \\ Psychiatric Hospital, Thessaloniki, Greece and ${ }^{4} \mathrm{~B}$ ' Acute Ward, Psychiatric Hospital, Thessaloniki, Greece \\ * Corresponding author
}

from International Society on Brain and Behaviour: 2nd International Congress on Brain and Behaviour

Thessaloniki, Greece. 17-20 November 2005

Published: 28 February 2006

Annals of General Psychiatry 2006, 5(Suppl I):S276 doi:I0.I 186/I744-859X-5-SI-S276

\section{Case Report}

Induced delusional disorder (or shared paranoid disorder), also known as folie a' deux, is a relatively rare disorder typically characterized by the presence of similar psychotic symptoms in two or more individuals. However, the number of reports on delusions shared by more than two people is extremely small. Folie a' famille is a form of the psychopathological condition known as folie a' deux, where all the members of a family share the same delusions. Usually the "primary" case", i.e. the individual who first develops psychotic symptoms, can be distinguished from one or more "secondary" cases, in whom the symptoms are induced. The etiological studies of folie a" deux are grouped under two headings: i) genetically transmitted-structural factors; and ii) environmental-psychological factors.

The case history, clinical and diagnostic issues, and treatment of a family sharing the same delusion are presented. There were four members in the family: father, mother, two sisters. All four cases fulfilled modern operational definitions for induced delusional disorder in that: i) the partners were intimately associated, ii) they had identical delusional content, iii) there was an acceptance and support of the delusional ideas by all four members. The case history of all family members, as well as an extensive clinical examination of them, led to the conclusion that the youngest daughter was the "primary" case and the rest of them the "secondary" cases, even though the mother had long ago developed a paranoid personality disorder. At the age of twenty-four the youngest daughter while studying at the university far away from her family began to present atypical somatic symptoms, paranoid ideation with ideas of reference and delusions of persecution. Soon after she moved back home, it became clear that both parents and the sister also developed the same delusional symptoms.

The whole family abandoned their house and their jobs and started a purposeless roaming far away from their town in order to escape form their "persecutors". During this face, the family was involuntary admitted to the Psychiatric Hospital. The four persons were separated in four different psychiatric departments of the same hospital. Later, they were transferred to psychiatric clinics of four different towns. At that point an improvement of the father and the eldest sister was observed. An early discharge of the "primary" case gave them the opportunity to re-organise the whole paranoid system.

The whole cycle with involuntary admissions to the Psychiatric Hospital started again. During this phase (for various reasons) only the mother and the eldest sister received anti-psychotic medication. Furthermore, the separation of the family in different hospitals, although it is undoubtedly the appropriate therapeutic intervention, cannot be achieved at present due to bureaucratic reasons.

\section{Discussion}

It has been argued that the only "non-genetic" factors in the aetiology of schizophrenia are stochastic events affecting gene expression or structure. Therefore, shared or induced delusional disorders, folie a' deux and especially folie a famille, provide unique opportunities to consider 
the relative roles of genetic and environmental risk factors in the aetiology of psychotic illnesses.

\section{References}

I. Cuhadaroglou EC: Folie a' famille and separation-individuation. European Child and Adolescent Psychiatry 200I, 10:194-199.

2. Wenheimer PM, Barth N, Remschmidt H: Induced Delusional Disorder: A review of the concept and an unusual case of folie $a^{\prime}$ fammille. Psychopathology 2003, 36:37-45.

3. Mela M, Obenbe A, Farmer AE: Folie a quatre in a large Nigerian sub-ship. Schizophrenia Research 1997, 23:91-93.

4. Reif A, Pfuhlmann B: Folie $a^{\prime}$ deux versus genetically driven delusional disorder: case reports and nosological considerations. Comprehensive Psychiatry 2004, 45: I 55-160.

Publish with Bio Med Central and every scientist can read your work free of charge

"BioMed Central will be the most significant development for disseminating the results of biomedical research in our lifetime. "

Sir Paul Nurse, Cancer Research UK

Your research papers will be:

- available free of charge to the entire biomedical community

- peer reviewed and published immediately upon acceptance

- cited in PubMed and archived on PubMed Central

- yours - you keep the copyright

Submit your manuscript here:

http://www.biomedcentral.com/info/publishing_adv.asp 